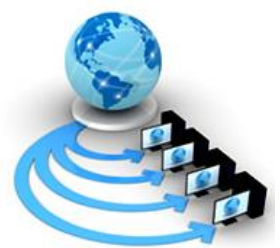

International Journal of Advanced Research in Computer Science

RESEARCH PAPER

\title{
COMPARATIVE STUDY OF RELIABILITY MODELS IN RESPECT OF PROFIT AND AVAILABILITY OF SINGLE UNIT SYSTEMS WITH DIFFERENT REPAIR POLICIES.
}

\author{
Dr. Meena Kumari \\ Asst. Professor, Statistics Department \\ Hindu Girls College, Sonipat, India
}

\begin{abstract}
In this Research paper two reliability models of a single unit system are analysed in detail using regenerative point technique. The unit fails completely via partial failure. There is single server who appears and disappears randomly from the system. However, he attends the system immediately at complete failure of the unit in Model-I. Server inspects the unit at its partial failure to see the possibility of on-line repair. If online repair is not possible, it is repaired in down state. The server cannot leave the system during inspection and repair. The distributions of failure time, random appearance and disappearance of the server are taken as negative exponential while that of inspection and repair time are arbitrary. All random variables are uncorrelated and independent to each other. The expressions for some reliability and economics measures are derived. The results for a particular case are also obtained to depict the behaviour of MTSF, availability and profit of the system models graphically.
\end{abstract}

Keywords:Single-unit system, Inspection, On-line Repair, Reliability and Profit Analysis

\section{INTRODUCTION}

In real life, it is observed that when a system is not repaired at the proper time and partially failed unit is taken out from the system for repair, the system suffers operational as well as economical loss. For example, when online repair of the system of an electric transformer is not done at its partial failure due to the defects in cooling, in temperature indicators and non-functioning of on-load tap changer, then it may be damaged completely. However, on-line repair of the electric transformer is not possible when it fails partially due to the problems in its protective system. In such a situation inspection of the system can be done to reveal the possibility of on-line repair. If on-line repair is not possible, its repair can be done in the down state. Several scholars including R.S. Naidu and M.N. Gopalan [1984] [1], K. Murari and V. Goyal [1984] [2] and Makaddis et al. [1989] [3]. have analysed reliability models ignoring the above observations under the assumptions that repair of the system is possible only at its complete failure and server never attends the system immediately. But sometimes it is not possible for the server to attend the system immediately may because of his pre-occupations. In such a situation, system remains down. Therefore, it becomes necessary to protect the operation of the working unit as long as possible after its partial failure so that reliability and profit of the system may increase. S.K. Singh [1989] [4] evaluated profit of a system with random appearance and disappearance of the server. In view of the above the present study focused on the analysis of two reliability models for a single unit system in which unit fails completely via partial failure. There is a single server who inspects the unit at its partial failure to examine the feasibility of on-line repair. If on-line repair of the unit is not feasible, it is repaired in down state, that is, after stopping the operation of the system. In Model-I, server appears and disappears randomly with some probability while in Model-II, he may be called immediately, whenever unit fails completely. The regenerative point technique is adopted to derive the expressions for some reliability and economic measure such as transition probabilities, mean sojourn times, mean time to system time failure (MTSF), steady state availability, busy period of the server, unexpected number of visits and profit function. The numerical results for a particular case are also obtained for both the models to draw the graphs.

System Description and Assumptions

1. The system consists of two single-unit models. Initially the unit is operative and fails completely via partial failure.

2. There is a single server who appears and disappears randomly with some probabilities from the system.

3. The server cannot leave the system while repairing the unit.

4. The server attends the system immediately when the system fails completely in Model-II.

5. The repair and inspection are perfect.

6. The unit under repair at partial failure mode in down-state cannot fail.

7. Each unit has an exponential distribution of time to failures while distributions of repairs and inspections are arbitrary.

8. All the random variables are mutually independent.

\section{NOTATIONS}

r1/r2: Failure rate from N-Mode to P-moe/P-mode to Fmode

A/NA:Server is available/not available

$\mathbf{a} / \mathbf{b}$ :Probability that on-line repair of partially failed unit is possible/not possible

$\mathbf{x} / \mathbf{y}$ :Constant rate of appearance/disappearance of server $\mathbf{h}(\mathbf{t}), \mathbf{H}(\mathbf{t}):$ p.d.f. And c.d.f. Of inspection time by the server No: Unit in N-mode and operative 
P-mode/F-mode: Unit in partially failure mode/complete failure mode

$\boldsymbol{\theta}_{1}$ :Repair rate of the partially failed unit

Pwi/PUr/PUi/PUrd:Unit in partially failure mode and waiting for inspection/ under repair / under inspection/under repair in down state

Fwr/FUr:Unit in Complete failure mode and waiting for repair/under repair

$\boldsymbol{q}_{i j}(\boldsymbol{t}), \boldsymbol{Q}_{i j}(\boldsymbol{t}):$ p.d.f and c.d.f. of transition times from states $S_{i}$ to state $S_{j}$.

$\boldsymbol{M}_{\boldsymbol{i}}(\boldsymbol{t}):$ P [ system up initially in state $S_{i}$ up to time t without making any transition to any other regenerative state].

$\boldsymbol{W}_{\boldsymbol{i}}(\boldsymbol{t}): \mathrm{P}$ [server is busy in state $S_{i}$ upto time t without making any transition to any other regenerative state].

$\boldsymbol{m}_{\boldsymbol{i j}}$ : Contribution to mean sojourn time in state $S_{i}$ belonging to regenerative state.

(S)/C: Symbol for Stieltjesconvolution/Laplace convolution. /*: Symbol for Laplace Stieltjes Transform (L.S.T)/Laplace Transform (L.T)

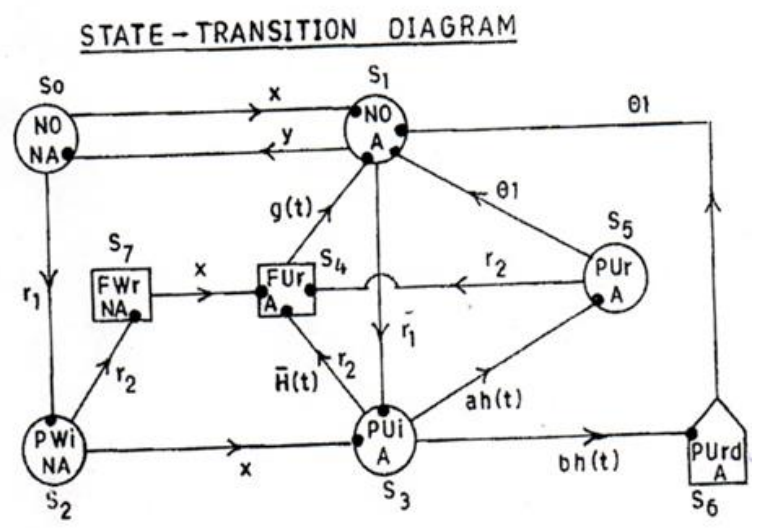

Fig. 1

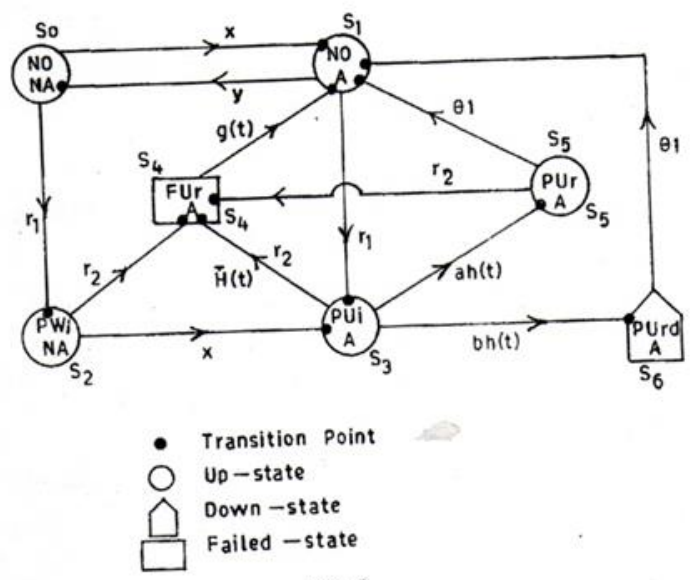

Fig. 2

The following are the possible transition states of the system models

For Model-I

$S_{0}=\left(N_{o}, N A\right) \quad S_{3}=\left(P U_{i}, A\right) \quad S_{6}=\left(P U_{r d}, A\right)$

$S_{1}=\left(N_{o}, A\right) \quad S_{4}=\left(F U_{r}, A\right) \quad S_{7}=\left(F W_{r}, N A\right)$

$S_{2}=\left(P W_{i}, N A\right) S_{5}=\left(P U_{r}, A\right)$
All these state are regenerative states.

For Model-II

The states $S_{i}(i=1,2,3,4,5,6)$ are same as in model I.

All these state are regenerative.

Transition Probabilities and Mean Sojourn Times

Simple probabilistic considerations yield the following expression for the non-zero elements $P_{i j}$ by taking all distributions exponential as $P_{i j}=Q_{i j}(\infty)=\int q_{i j}(t) d t$.

For Model-I

$$
\begin{array}{ll}
p_{01}=\frac{x}{\left(x+r_{1}\right)} & p_{02}=\frac{r_{1}}{\left(x+r_{1}\right)} \\
p_{10}=\frac{y}{\left(y+r_{1}\right)} & p_{13}=\frac{r_{1}}{\left(y+r_{1}\right)} \\
p_{23}=\frac{x}{\left(x+r_{2}\right)} & p_{27}=\frac{r_{2}}{\left(x+r_{2}\right)} \\
p_{34}=\frac{r_{2}}{\left(r_{2}+\theta\right)} & p_{35}=\frac{a_{\theta}}{\left(r_{2}+\theta\right)} \\
p_{36}=\frac{b_{\theta}}{\left(r_{2}+\theta\right)} ; & P_{41,74,61}=1 \\
p_{51}=\frac{\theta_{1}}{\left(r_{2}+\theta_{1}\right)} & p_{54}=\frac{r_{2}}{\left(r_{2}+\theta_{1}\right)}
\end{array}
$$

It can be verified that

$$
\begin{gathered}
p_{01}+p_{02}=p_{10}+p_{13}=p_{23}+p_{27} \\
=p_{34}+p_{35}+p_{36}=p_{41}=p_{74}=p_{51}+p_{54}=p_{61}=1
\end{gathered}
$$

The mean Sojourn time $\left(\mu_{i}\right)$ is the state $S_{i}$ are

$$
\begin{aligned}
& \mu_{0}=\int_{0}^{\infty} P(T>t) d t=\frac{1}{x+r_{1}} \\
& \mu_{1}=\frac{1}{\left(y+r_{1}\right)} ; \mu_{2}=\frac{1}{\left(x+r_{2}\right)} ; \mu_{3}=1-h *\left(r_{2}\right) \\
& \mu_{4}=-g *^{\prime}(0)=\int_{0}^{\infty} g(t) d t \\
& \mu_{5}=\frac{1}{\left(r_{1}+\theta\right)} \mu_{6}=\frac{1}{\theta_{1}} ; \mu_{7}=\frac{1}{x}
\end{aligned}
$$

For Models-II

The transition probabilities

$p_{01}, p_{02}, p_{10}, p_{13}, p_{23}, p_{35}, p_{36}, p_{41,74,61}, p_{51}, p_{54}$ same as defined in model 1 and remaining are

$$
p_{24}=\frac{r_{2}}{\left(x+r_{2}\right)} \quad p_{34}=\frac{r_{2}}{(x+\theta)}
$$

The mean Sojourn times $\left(\mu_{i}\right)$ in the state $S_{i}$ are ;

$\mu_{3}=\frac{1}{\left(r_{2}+\theta\right)}, \quad \mu_{4}=\frac{1}{\theta_{2}}$ and remaining $\mu_{i}$ for $\mathrm{i}=0,1,2,5,6$ are same as devised for model-I

It can be verified that

$p_{01}+p_{02}=p_{10}+p_{13}=p_{23}+p_{24}=p_{34} p_{35}+p_{36}=p_{51}+p_{54}=$ $p_{61}=1$

Mean Time to System Failure (MTSF)

Let $\phi_{\mathrm{i}}(\mathrm{t})$ be the c.d.f,. of the first passage time from regenerative state $S_{i}$ to a failed state. We have the following recursive relations for $\phi_{\mathrm{i}}(\mathrm{t})$ :

For Model-I

$$
\begin{aligned}
& \phi_{0}(\mathrm{t})=\mathrm{Q}_{01}(\mathrm{t})\left(\mathrm{S} \phi_{1}(\mathrm{t})+\mathrm{Q}_{02}(\mathrm{t})\left(\mathrm{S} \phi_{2}(\mathrm{t})\right.\right. \\
& \phi_{1}(\mathrm{t})=\mathrm{Q}_{01}(\mathrm{t})\left(\mathrm{S} \phi_{0}(\mathrm{t})+\mathrm{Q}_{13}(\mathrm{t})\left(\mathrm{S} \phi_{3}(\mathrm{t})\right.\right. \\
& \phi_{2}(\mathrm{t})=\mathrm{Q}_{23}(\mathrm{t})\left(\mathrm{S} \phi_{3}(\mathrm{t})+\phi_{27}(\mathrm{t})\right. \\
& \phi_{3}(\mathrm{t})=\mathrm{Q}_{35}(\mathrm{t})\left(\mathrm{S} \phi_{5}(\mathrm{t})+\mathrm{Q}_{34}(\mathrm{t})+\mathrm{Q}_{36}(\mathrm{t})\right. \\
& \phi_{1}(\mathrm{t})=\mathrm{Q}_{51}(\mathrm{t})\left(\mathrm{S} \phi_{1}(\mathrm{t})+\mathrm{Q}_{54}(\mathrm{t})\right.
\end{aligned}
$$

Taking L.S.T. of the above relations (4) and solving for $\widetilde{\emptyset_{0}}(\mathrm{~s})$. Using this, we have

$$
\operatorname{MTSF}\left(\mathrm{T}_{1}\right)=\lim _{s \rightarrow 0} \frac{1-\widetilde{\emptyset_{0}}(s)}{s}=\frac{N 11}{D 11}
$$

where

$\mathrm{N}_{11}=\left(\mu_{0}+p_{23} \mu_{5}\right) \mathrm{z}_{1}+\mu_{1} \mathrm{z}_{2}+\left(\mu_{3}+p_{35} \mu_{5}\right) \mathrm{z}_{3}$

$\mathrm{D}_{11}=\mathrm{z}_{1}-\mathrm{p}_{10} \mathrm{z}_{2}$

and $z_{1}=1-p_{13} p_{35} p_{51}, z_{2}=p_{10}+p_{02} p_{23} p_{35} p_{51}, z_{3}=p_{01} p_{13}+p_{02} p_{23}$ For Model-II 
The Expressions for $\phi_{0}(\mathrm{t}), \phi_{1}(\mathrm{t}), \phi_{3}(\mathrm{t}), \phi_{5}(\mathrm{t})$ are same as given in Model-I while remaining is

$\phi_{1}(\mathrm{t})=\mathrm{Q}_{23}(\mathrm{t}) \subseteq \phi_{1}(\mathrm{t})+\mathrm{Q}_{24}(\mathrm{t})$

taking L.S.T. of the above relation (6) and solving for $\widetilde{\emptyset_{0}}(\mathrm{~s})$ using this, we have

$$
\operatorname{MTSF}\left(\mathrm{T}_{2}\right)=\lim _{\mathrm{s} \rightarrow 0} \frac{1-\widetilde{\phi_{0}}(s)}{s}=\frac{N 21}{D 21} \text { where }
$$

where $\mathrm{N}_{21}=\left(\mu_{0}+p_{02} \mu_{2}\right) \mathrm{z}_{1}+\mu_{1} \mathrm{z}_{2}+\left(\mu_{3}+p_{35} \mu_{5}\right) \mathrm{z}_{3}$

and

$\mathrm{D}_{11}=\mathrm{z}_{1}-\mathrm{p}_{10} \mathrm{z}_{2}$ and $\mathrm{z}_{1}, \mathrm{z}_{2}, \mathrm{z}_{3}$ are already specified.

Availability Analysis

For Model-I

$\mathrm{A}_{0}(\mathrm{t})=\mathrm{M}_{0}(\mathrm{t})+\mathrm{q}_{01}(\mathrm{t}) \odot \mathrm{A}_{1}(\mathrm{t})+\mathrm{q}_{02}(\mathrm{t}) \odot \mathrm{A}_{2}(\mathrm{t})$

$A_{1}(t)=M_{1}(t)+q_{10}(t) @ A_{0}(t)+q_{13}(t) \odot A_{3}(t)$

$\mathrm{A}_{2}(\mathrm{t})=\mathrm{M}_{2}(\mathrm{t})+\mathrm{q}_{23}(\mathrm{t}) \odot \mathrm{A}_{3}(\mathrm{t})+\mathrm{q}_{27}(\mathrm{t}) \odot \mathrm{A}_{7}(\mathrm{t})$

$\mathrm{A}_{3}(\mathrm{t})=\mathrm{M}_{3}(\mathrm{t})+\mathrm{q}_{35}(\mathrm{t}) \odot \mathrm{A}_{5}(\mathrm{t})+\mathrm{q}_{34}(\mathrm{t}) \odot \mathrm{A}_{4}(\mathrm{t})+\mathrm{q}_{02}(\mathrm{t}) \subseteq \mathrm{A}_{6}(\mathrm{t})$

$\mathrm{A}_{4}(\mathrm{t})=\mathrm{q}_{41}(\mathrm{t}) \odot \mathrm{A}_{1}(\mathrm{t})$

$\mathrm{A}_{5}(\mathrm{t})=\mathrm{M}_{5}(\mathrm{t})+\mathrm{q}_{51}(\mathrm{t}) \odot \mathrm{A}_{1}(\mathrm{t})+\mathrm{q}_{54}(\mathrm{t}) \odot \mathrm{A}_{4}(\mathrm{t})$

$\mathrm{A}_{6}(\mathrm{t})=\mathrm{q}_{61}(\mathrm{t}) \odot \mathrm{A}_{1}(\mathrm{t})$

$\mathrm{A}_{7}(\mathrm{t})=\mathrm{q}_{74}(\mathrm{t}) @ \mathrm{~A}_{4}(\mathrm{t})$

where

$\mathrm{M}_{0}(\mathrm{t})=\mathrm{e}-(x+r 1) t \mathrm{dt}, \quad \mathrm{M}_{0}(\mathrm{t})=\mathrm{e}-(y+r 1) t \mathrm{dt}$

$\mathrm{M}_{2}(\mathrm{t})=\mathrm{e}-(x+r 1) t \mathrm{dt}, \quad \mathrm{M}_{3}(\mathrm{t})=\mathrm{e}^{-\mathrm{r} 2 \mathrm{t}} H(t) \mathrm{dt}$

$\mathrm{M}_{5}(\mathrm{t})=\mathrm{e}-(r 2+\theta) t \mathrm{dt}$

Taking the L.T. of the relation (7) and solving for $\mathrm{A}_{0}{ }^{*}(\mathrm{~s})$ and by using this, we get the steady availability as:

$\mathrm{A}_{10}(\infty)=\lim _{\mathrm{s} \rightarrow \mathrm{O}} \mathrm{A} 0 *(\mathrm{~s})=\frac{N 12}{D 12}$

where $\mathrm{N}_{12}=\left(\mu_{0}+p_{02} \mu_{2}\right) \mathrm{p}_{10}+\mu_{1}+\left(\mu_{3}+p_{35} \mu_{5}\right)$

$\mathrm{D}_{12}=\left(\mu_{0}+p_{02} \mu_{2}\right) \mathrm{p}_{10}+\mu_{1}+\mathrm{z}_{11}\left(\mu_{3}+z_{12} \mu_{4}+\mathrm{p}_{35} \mu_{5}\right.$

$\left.+\mathrm{p}_{36} \mu_{6}\right)+\left(\mu_{7}+\mu_{4}\right)$

and

$\mathrm{z}_{11}=\mathrm{p}_{13}+\mathrm{p}_{10} \mathrm{p}_{02} \mathrm{p}_{23}$

$\mathrm{z}_{12}=\mathrm{p}_{34}+\mathrm{p}_{35} \mathrm{p}_{54}$

$\mathrm{z}_{11}=\mathrm{p}_{10} \mathrm{p}_{02} \mathrm{p}_{27}$

For Model-II

$\mathrm{A}_{2}(\mathrm{t})=\mathrm{M}_{2}(\mathrm{t})+\mathrm{q}_{23}(\mathrm{t}) \odot \mathrm{A}_{3}(\mathrm{t})+\mathrm{q}_{24}(\mathrm{t})\left(\mathrm{A}_{4}(\mathrm{t})\right.$ and

$\mathrm{A}_{0}(\mathrm{t}), \mathrm{A}_{1}(\mathrm{t}), \mathrm{A}_{2}(\mathrm{t}), \mathrm{A}_{3}(\mathrm{t}), \mathrm{A}_{4}(\mathrm{t}), \mathrm{A}_{5}(\mathrm{t}), \mathrm{A}_{6}(\mathrm{t})$ are same as in

Model-I

Where $\mathrm{M}_{0}(\mathrm{t}), \mathrm{M}_{1}(\mathrm{t}), \mathrm{M}_{3}(\mathrm{t}), \mathrm{M}_{5}(\mathrm{t})$ are same as in model 1 and and $\mathrm{M}_{2}(\mathrm{t})=\mathrm{e}-(x+r 2) t$

Taking L.T. of relation (9) and solving for $\mathrm{A}_{0}{ }^{*}$ (s) by using this, we get steady state availability as:

$\mathrm{A}_{20}(\infty)=\lim _{s \rightarrow 0} \mathrm{~S} \mathrm{~A}_{0}^{*}(\mathrm{~s})=\frac{N 22}{D 22}$

where

$\mathrm{D}_{22}=\left(\mu_{3}+p_{35} \mu_{5}+p_{36} \mu_{6}+z_{12} \mu_{4}\right) \mathrm{z}_{11}+\mu_{4} \mathrm{z}_{12}$

$\mathrm{Z}_{11}, \mathrm{Z}_{12}$ and are already specified.

Busy Period Analysis

Let $B_{i}(t)$ be the probability that the server is busy in repairing the unit at an instant ' $\mathrm{t}$ ' given that the system entered regenerative state $S_{i}$ at $\mathrm{t}=0$. The recursive relations for $B_{i}(t)$ are as follows:

$B_{i}(t)=W_{i}(t)+\sum_{i . j}$ qij(t)@Bj(t)

For Model-I

where $\mathrm{i}=\{0--7\}$ and

$\mathrm{j}=\{(1,2) ;(0,3) ;(3,7) ;(4,5,6,7) ;(1) ;(1,4) ;(1) ;(4)\}$.

Also $\mathrm{W}_{\mathrm{i}}(\mathrm{t})=0$ when $\mathrm{i}=\{0,1,2,7\}$

while remaining are:

$\mathrm{W}_{3}(\mathrm{t})=\mathrm{e}^{-\mathrm{r} 2 \mathrm{t}} H(t)$

$\mathrm{W}_{4}(\mathrm{t})=G(t)$

$\mathrm{W}_{5}(\mathrm{t})=\mathrm{e}-(\theta 1+r 2) t$
$\mathrm{W}_{6}(\mathrm{t})=\mathrm{e}-\theta 1 t$

For Model-II

We can obtain the recursive relations for $\mathrm{B}_{\mathrm{i}}(\mathrm{t})$ as given on

(11) fori $=(0,1,2,3,4,5)$ and

$\mathrm{j}=\{(1.2) ;(, 3) ;(3,4) ;(4,5,6) ;(1) ;(1,4) ;(1)\}$.

Also $\mathrm{W}_{\mathrm{i}}(\mathrm{t})=0$ for $\mathrm{i}=0,1,2$

While remaining are

$\mathrm{W}_{3}(\mathrm{t})=\mathrm{e}^{-\mathrm{r} 2 \mathrm{t}} H(t)$

$\mathrm{W}_{4}(\mathrm{t})=G(t)$

$\mathrm{W}_{5}(\mathrm{t})=\mathrm{e}-(\theta 1+r 2) t$

$\mathrm{W}_{6}(\mathrm{t})=\mathrm{e}-\theta 1 t$

Taking L.T. of the above relation (11) and determine

$\mathrm{B}_{0}{ }^{*}(\mathrm{~s})$ for each model. Using this, we get in the long run, the time for which server is busy as

$\mathrm{B}_{0}(\infty)=\lim _{s \rightarrow 0} \mathrm{~s} \mathrm{~B}_{0}{ }^{*}(\mathrm{~s})$

For Model-I

$\mathrm{B}_{10}=\frac{N 12}{D 11}$

where

$\mathrm{N}_{12}=\left(\mu_{3}+p_{35} \mu_{5}+p_{36} \mu_{6}+\mathrm{z}_{12} \mu_{4}\right) \mathrm{z}_{11}+\mu_{4} \mathrm{z}_{13}$ and $\mathrm{D}_{11}$ is already defined.

For Model-II

$\mathrm{B}_{20}=\frac{N 23}{D 22}$

where

$\mathrm{N}_{23}=\left(\mu_{3}+p_{35} \mu_{5}+p_{36} \mu_{6}+\mathrm{z}_{12} \mu_{4}\right) \mathrm{z}_{11}+\mu_{4} \mathrm{Z}_{13}$

$\mathrm{Z}_{11}, \mathrm{Z}_{12}, \mathrm{z}_{13}$ and $\mathrm{D}_{22}$ are already defined.

Expected Number of Visits by the Service

Let $N_{i}(t)$ be the expected number of visit by the server in

$(0, t)$ given that the system entered the regenerative state $i$ at $\mathrm{t}=0$. The $N_{i}(t)$ are given

For Model-I

$\mathrm{N}_{0}(\mathrm{t})=\mathrm{Q}_{01}(\mathrm{t})\left(\mathrm{S}\left[1+\mathrm{N}_{1}(\mathrm{t})\right]+\mathrm{Q}_{02}(\mathrm{t})\left(\mathrm{N}_{2}(\mathrm{t})\right.\right.$

$\mathrm{N}_{1}(\mathrm{t})=\mathrm{Q}_{10}(\mathrm{t})(\mathrm{S}) \mathrm{N}_{0}(\mathrm{t})+\mathrm{Q}_{13}(\mathrm{t})(\mathrm{S}) \mathrm{N}_{3}(\mathrm{t})$

$\mathrm{N}_{2}(\mathrm{t})=\mathrm{Q}_{23}(\mathrm{t}) S\left[1+\mathrm{N}_{3}(\mathrm{t})\right]+\mathrm{Q}_{27}(\mathrm{t})\left(\mathrm{S} \mathrm{N}_{7}(\mathrm{t})\right.$

$\mathrm{N}_{3}(\mathrm{t})=\mathrm{Q}_{35}(\mathrm{t})(\mathrm{S}) \mathrm{N}_{5}(\mathrm{t})+\mathrm{Q}_{36}(\mathrm{t})\left(\mathrm{S} \mathrm{N}_{6}(\mathrm{t})+\mathrm{Q}_{34}(\mathrm{t})(\mathrm{S}) \mathrm{N}_{4}(\mathrm{t})\right.$

$\mathrm{N}_{4}(\mathrm{t})=\mathrm{Q}_{41}(\mathrm{t})(\mathrm{S}) \mathrm{N}_{1}(\mathrm{t})$

$\mathrm{N}_{5}(\mathrm{t})=\mathrm{Q}_{51}(\mathrm{t})\left(\mathrm{N}_{1}(\mathrm{t})+\mathrm{Q}_{54}(\mathrm{t})\left(\mathrm{S} \mathrm{N}_{4}(\mathrm{t})\right.\right.$

$\mathrm{N}_{6}(\mathrm{t})=\mathrm{Q}_{61}(\mathrm{t})(\mathrm{S}) \mathrm{N}_{1}(\mathrm{t})$

$\mathrm{N}_{7}(\mathrm{t})=\mathrm{Q}_{74}(\mathrm{t})(\mathrm{S})\left[1+\mathrm{N}_{4}(\mathrm{t})\right]$

Taking the L.S.T. of the above relation (14) and solving for $\widetilde{N_{0}}$ the expected number of visits per unit time are given by

$\mathrm{N}_{0}(\infty)=\lim _{s \rightarrow 0} \mathrm{~s} \widetilde{N_{0}} *(\mathrm{~s})$. .. (15)

For Model-I

$\mathrm{N}_{10}=\frac{N 13}{D 11}$

where $\mathrm{N}_{13}=\mathrm{p}_{10}$ and $\mathrm{D}_{11}$ is already defined.

For Model-II

The expressions for $\mathrm{N}_{\mathrm{i}}(\mathrm{t})$ for $\mathrm{i}=(0,1,3,4,5,6)$ are the same as specified in Model-I

and remaining are

$\mathrm{N}_{2}(\mathrm{t})=\mathrm{Q}_{23}(\mathrm{t})(\mathrm{S})\left[1+\mathrm{N}_{3}(\mathrm{t})\right]+\mathrm{Q}_{24}(\mathrm{t})(\mathrm{S})\left[1+\mathrm{N}_{4}(\mathrm{t})\right]$

$\mathrm{N}_{20}=\frac{N 24}{D 12}$

Where $\mathrm{N}_{24}=\mathrm{p}_{10}$ and $\mathrm{D}_{22}$ is already specified.

Cost Analysis

Profits incurred to the system for both the models in steadystate are given by

$\mathrm{P}_{1}=\mathrm{K}_{1} \mathrm{~A}_{10}-\mathrm{K}_{2} \mathrm{~B}_{10}-\mathrm{K}_{3} \mathrm{~N}_{10}$

$\mathrm{P}_{1}=\mathrm{K}_{1} \mathrm{~A}_{20}-\mathrm{K}_{2} \mathrm{~B}_{20}-\mathrm{K}_{3} \mathrm{~N}_{20}$

Where

$\mathrm{K}_{1}=$ Fixed revenue per unit up time of the system 
$\mathrm{K}_{2}=$ Fixed cost per unit time for which server is busy

$\mathrm{K}_{3}=$ Fixed cost per unit visit by the server

Particular Case

For Model- I

$\operatorname{MTSF}\left(\mathrm{T}_{1}\right)=\frac{N 1}{D 1}$

where

$\mathrm{N} 1=\left[\mathrm{a} \theta \theta 1 \mathrm{r}\left[\mathrm{Z}_{1} \mathrm{R}_{12}\left(\mathrm{x}+\mathrm{r}_{1}+\mathrm{r}_{2}\right)\left(\mathrm{y}+\mathrm{r}_{1}\right)+\mathrm{x} \mathrm{Z}_{2}\right]+\mathrm{R}_{11} \mathrm{Z}_{3}\left(\mathrm{r}_{2}+\theta_{1}\right.\right.$

$\left.+\mathrm{a} \theta)\left(\mathrm{y}+\mathrm{r}_{1}\right)\right] / \mathrm{ax}\left(\mathrm{y}+\mathrm{r}_{1}\right) \theta \theta_{1} \mathrm{r}_{1}$

$\mathrm{D}_{1}=\left[\mathrm{Z}_{1}\left(\mathrm{y}+\mathrm{r}_{1}\right)-\mathrm{y} \mathrm{Z}_{2}\right] /\left(\mathrm{y}+\mathrm{r}_{1}\right)$ and

$\mathrm{R}_{11}=\frac{a \theta \theta 1 r 1}{(r 2+\theta)(r 2+\theta 1)}, \mathrm{R}_{11}=\frac{x}{(r 1+x)(r 2+x)}$

$\mathrm{Z}_{1}=\frac{(y+r 1)-R 11}{(y+r 1)}, \mathrm{Z}_{2}=\mathrm{R}_{12}\left(\mathrm{x}+\mathrm{r}_{2}+\mathrm{R}_{11}\right)$

$\mathrm{Z}_{3}=\mathrm{R}_{12} \mathrm{r}_{1}\left(\mathrm{x}+\mathrm{y}+\mathrm{r}_{1}+\mathrm{r}_{2}\right) /\left(\mathrm{y}+\mathrm{r}_{1}\right)$

Availability

$$
\left(A_{10}\right)=N_{11} / D_{11} \ldots(18)
$$

where

$\mathrm{N}_{11}=\left(\mathrm{H}_{1}+\mathrm{H}_{4}\right), \quad \mathrm{D}_{11}=\left(\mathrm{H}_{1}+\mathrm{H}_{2}+\mathrm{H}_{3}\right)$ and

$\mathrm{H}_{1}=\left(\mathrm{x}+\mathrm{yR}_{12}\left(\mathrm{x}+\mathrm{r}_{1}+\mathrm{r}_{2}\right)\right) / \mathrm{x}\left(\mathrm{y}+\mathrm{r}_{1}\right)$

$\mathrm{H}_{2}=\mathrm{Z}_{11}\left[\mathrm{Z}_{12}\left(\mathrm{r}_{2}+\theta\right)\left(\mathrm{r}_{2}+\theta\right) \theta_{1}+\theta_{2}\left(\mathrm{r}_{2}+\theta_{1}\right)\left(\theta_{1}+\mathrm{b} \theta\right)+a \theta \theta 1 \theta 2\right] /$

$(\theta 1 \theta 2(r 2+\theta 1)(\theta 1+b \theta))$

\section{CONCLUSION}

Fig.3 shows the graphical trend of MTSF with respect to failure rate $r_{2}$ for different sets of values of inspection $\operatorname{rete}(\theta)$, failure rate $\left(\mathrm{r}_{1}\right)$ and repair rate $\left(\theta_{1}\right)$. From this, we conclude the MTSF decreases with the increase of failure rates $r_{1}$ and $r_{2}$. However, it further increases if repair rate $\left(\theta_{1}\right)$ increases and decreases by the increase of inspection rate $(\theta)$.Fig. 4 and 5 show the behaviour of availability of both models respectively w.r.t. Failure rate $r_{2}$ and from these figures we see that availability decreases with the increase of failure rate $\left(r_{2}\right)$ and increases with the increase of inspection rate $(\theta)$. Further, availability of Model-II is greater than that of Model-I. Figures. 6 and 7 represent the variations of profits of both models respectively w.r.t. Failure rate $\left(\mathrm{r}_{2}\right)$ and cost of busy period of server and under some casesModel-I is profitable as compared to Model-II.

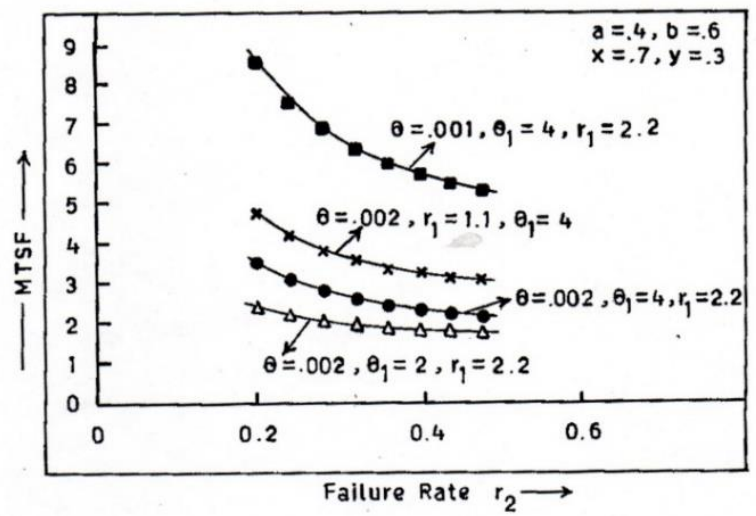

Fig. 3
$\mathrm{H}_{3}=\mathrm{Z}_{13}\left(\mathrm{x}+\theta_{2}\right) / \mathrm{x} \theta_{2}$

$\mathrm{H}_{4}=\mathrm{Z}_{11} \mathrm{R}_{11}\left(\mathrm{r}_{2}+\theta 1+\mathrm{a} \theta\right) / \mathrm{a} \theta \theta_{1} \mathrm{r}_{1}$

$\mathrm{Z}_{11}=\mathrm{r}_{1}\left(1+\mathrm{R}_{12} \mathrm{y}\right) /\left(\mathrm{y}+\mathrm{r}_{1}\right)$

$\mathrm{Z}_{12}=\left(\mathrm{R}_{12} \mathrm{r}_{2}\left(\mathrm{r}_{2}+\theta_{1}+\mathrm{a} \theta\right) / \mathrm{a} \theta \theta_{1} \mathrm{r}_{1}\right.$

$\mathrm{Z}_{13}=\mathrm{R}_{12} \mathrm{yr}_{1} \mathrm{r}_{2} / \mathrm{x}\left(\mathrm{y}+\mathrm{r}_{1}\right)$

Busy Period $\left(\mathrm{B}_{10}\right)=\frac{N 12}{D 11}$

where

$\mathrm{N}_{12}=\frac{H 2 D 2+Z 13}{\theta 2}$

Expected Number of visits

$\left(\mathrm{N}_{10}\right)=\mathrm{y} /\left(\mathrm{y}+\mathrm{r}_{1}\right)$

For Model-II

$\mathrm{T}_{2}=\frac{N 21}{D 21}=\frac{N 1}{D 1}$

Availability $\left(\mathrm{A}_{20}\right)=\frac{N 11}{D 12}$

whereD $_{12}=\frac{(H 1+H 2) \theta 2+Z 13}{\theta 2}$

Busy Period $\left(\mathrm{B}_{20}\right)=\frac{N 12}{D 12}$

Expected Number of Visits $\left(\mathrm{N}_{20}\right)=\frac{N 13}{D 12}$

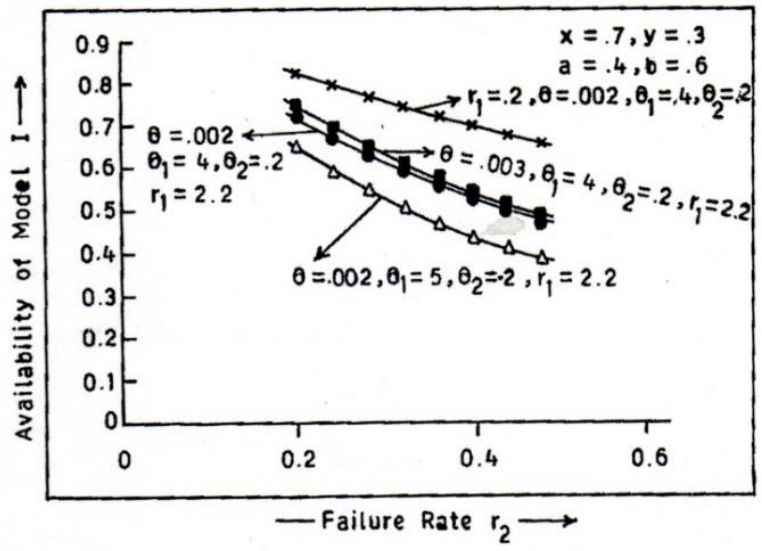

Fig. 4

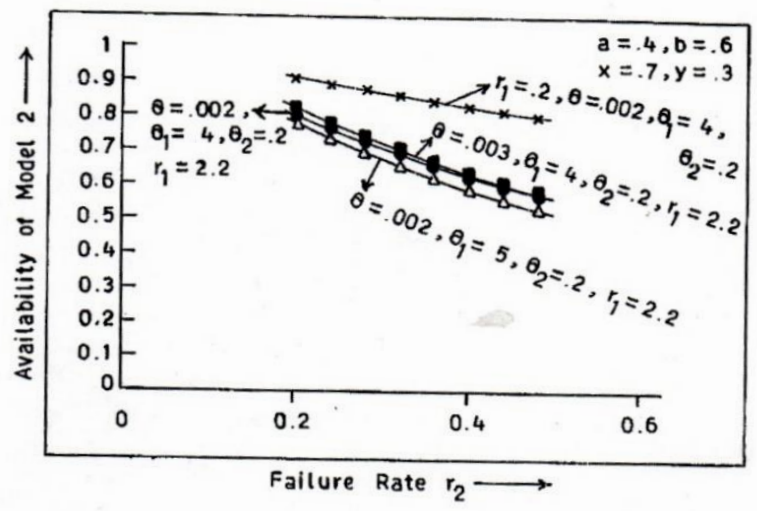

Fig. 5 
Profit of Modei I

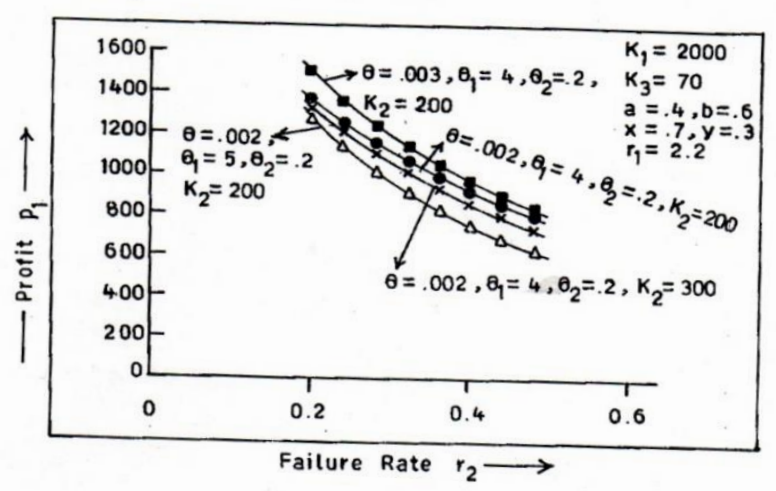

Protit of 2nd Model

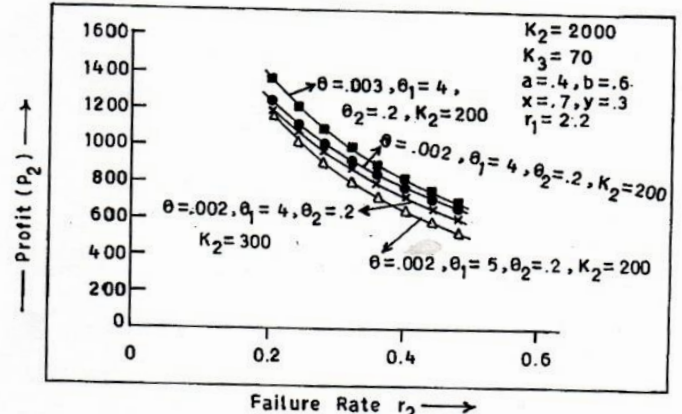

Fig. 7

\section{REFERENCES}

1. R.S. Naidu and M.N. Gopalan 1984: Cost benefit analysis of one server 2-unit system subject to arbitrary failure inspection and repair reliability engineering volume 8, pp 11.

2. K. Murari and V. Goyal 1984: Comparison 2-unit cold standby reliability models with three types of repair facilities. Microelectronics Reliability. volume 24(1), pp. 3 5-49.

3. G.S Mokkadis, S.S. Elias and S. W. Labib 1989: On a twounit redundant system with three modes and administrative delay in repair, Microelectronics Reliability, Vol.9. pp 511515

4. S.K. Singh 1989: Profit evaluation of a two-unit cold standby system with random appearance and disappearance time of the service facility Microelectronics Reliability. volume 29. pp 705- 709 . 